\title{
Biomaterials with Persistent Growth Factor Gradients in vivo Accelerate Vascularized Tissue
}

\section{Formation}

Banu Akar ${ }^{1,2}$, Bin Jiang ${ }^{1}$, Sami I. Somo ${ }^{1,2}$, Alyssa A. Appel ${ }^{1}$, Jeffery C. Larson ${ }^{1}$, Kenneth M. Tichauer ${ }^{1}$, Eric M. Brey ${ }^{1,2, *}$

1. Department of Biomedical Engineering, Illinois Institute of Technology

2. Research Service, Hines Veterans Administration Hospital

* Corresponding Author

Illinois Institute of Technology, Department of Biomedical Engineering 3255 South Dearborn Street

Chicago, IL 60616

United States

Research Service, Hines Veterans Administration Hospital

Hines, IL

United States

brey@iit.edu

Phone: 3125675098

Fax: 3125675707 


\section{Abstract}

Gradients of soluble factors play an important role in many biological processes, including blood vessel assembly. Gradients can be studied in detail in vitro, but methods that enable the study of spatially distributed soluble factors and multi-cellular processes in vivo are limited. Here, we report on a method for the generation of persistent in vivo gradients of growth factors in a three-dimensional (3D) biomaterial system. Fibrin loaded porous poly (ethylene glycol) (PEG) scaffolds were generated using a particulate leaching method. Platelet derived growth factor BB (PDGF-BB) was encapsulated into poly (lactic-co-glycolic acid) (PLGA) microspheres which were placed distal to the tissue-material interface. PLGA provides sustained release of PDGF-BB and its diffusion through the porous structure results in gradient formation. Gradients within the scaffold were confirmed in vivo using near-infrared fluorescence imaging and gradients were present for more than 3 weeks. The diffusion of PDGF-BB was modeled and verified with in vivo imaging findings. The depth of tissue invasion and density of blood vessels formed in response to the biomaterial increased with magnitude of the gradient. This biomaterial system allows for generation of sustained growth factor gradients for the study of tissue response to gradients in vivo.

Keywords: Gradient; Biomaterials; Vascularization; PDGF-BB; Near Infrared Fluorescence imaging. 


\section{Introduction}

Gradients of soluble biochemical signals exist in many biological processes, including angiogenesis [1], morphogenesis [2], wound healing [3], immune response [4], embryonic development [5] and cancer [6]. Many tissue-engineering applications focus on delivery of biochemical signals, particularly growth factors, to promote the development of vascularized tissues. However, the typical approach to temporal delivery of growth factors from polymeric materials does not allow control over spatial distribution in vivo. In a typical tissue environment, vascular cells respond to spatial gradients of proteins [7]. The gradient affects the direction, structure and rate of cell invasion and network formation. Gradient generating systems have the potential to enhance the formation of engineered tissues and allow for controlled study of biological processes in vivo.

In the fields of tissue engineering and regenerative medicine, biomaterial strategies that promote vascularized tissue formation are essential for engineering clinically relevant tissue volumes. A stable microvascular network is essential for normal tissue function. Tissues are typically limited to a few micrometers $(\mu \mathrm{m})$ in thickness in the absence of a functional vasculature [8]. The design of biomaterial scaffolds plays an important role in influencing the rate of microvascular network formation. The incorporation of growth factors into the scaffold with spatial and temporal control could serve as a method to enhance vascular network formation.

A number of techniques have been applied for the creation of gradients within biomaterials including diffusion [9,10], infusion [11,12], micro-contact printing [13], and microfluidic [14,15] systems. Microfluidic systems result in well-defined gradients of biochemical signals but are limited to in vitro settings due to the requirement of continuous source/sink reservoirs. Other methods allow for complex spatial distributions prior to implantations but uncontrolled remodeling of the gradients occurs rapidly upon implantation in vivo. Generating persistent gradients in vivo is challenging. Significant research has been performed on systems in vitro but in vivo study has been limited [16-19]. Recently, a gradient 
hydrogel was generated using an electrospraying technique and implanted into mice. This system was limited in volume (240 $\mu \mathrm{m}$ thickness) and no data was provided on the existence of gradients in vivo after implantation [20]. There is a significant need for systems that enable the generation of persistent gradients in vivo for the study and control of biological processes.

We developed a method for providing persistent growth factor gradients with an adjustable gradient magnitude in vivo. This method is illustrated by generating persistent gradients of platelet-derived growth factor (PDGF-BB) within fibrin/poly (ethylene glycol) (PEG) composite scaffolds. PDGF-BB was chosen as it promotes angiogenesis, directs cell migration and is involved in vessel maturation and stabilization [21,22]. In this approach, the PDGF-BB loaded poly (lactic-co-glycolic acid) (PLGA) microspheres are trapped within a degradable polymer layer poly (ethylene glycol l-lactic acid) (PEGPLLA) that is oriented distal to the biomaterial-tissue interface. Gradient properties can be controlled by varying the degradation rate of gradient layer components or dose of PDGF-BB delivered. The characteristics of the gradient were evaluated using a transport model and confirmed with near infrared fluorescence imaging. This system was then used to investigate the influence of PDGF-BB gradients on vascularized tissue formation within the biomaterial scaffold. To our knowledge, this is the first study to verify the presence of persistent growth factor gradients within a biomaterial system in vivo. 


\section{Materials and Methods}

\subsection{Materials}

Polyethylene glycol (PEG, $\mathrm{Mw} \approx 8000$ ), fibrinogen from human plasma (Fg, 50-70\% protein), thrombin from human plasma (Tb), 2-hydroxy-2-methylpropiophenone (Irgacure 1173), acryloyl chloride (98\%), thriethylamine (TEA, 99.5\%), PEG (Mw $\approx 3400)$, 3,6-dimethyl-1,4- dioxane-2,5-dione (l-lactide), Tin(II) 2-ethylhexanoate, Poly (lactic-co-glycolic acid) (PLGA 50:50, Mw = 7,00017,000), poly(vinyl alcohol) (PVA, $\mathrm{Mw}=13,000-23,000)$, bovine serum albumin (BSA), sucrose (>99.5\%), magnesium hydroxide (95\%), PKH-26 red fluorescent dye were obtained from SigmaAldrich (St. Louis, MO). Sodium chloride (99.5\%), dichloromethane (DCM, 99.9\%), ethyl ether (anhydrous), phosphate-buffered saline (PBS), Iodine 125 was obtained from Perkin Elmer Inc. (Waltham, MA). Recombinant rat PDGF-BB with carrier protein was obtained from R\&D Systems (Minneapolis, MN). Indocyanine green (ICG, 80\% dye content) was provided by Sigma-Aldrich (St. Louis, MO). IRDye 800CW (infrared dye) was obtained from Li-Cor Bioscience (Lincoln, NE).

\subsection{Scaffold Preparation}

\subsubsection{PEG-DA and PEG-PLLA-DA Synthesis}

PEG-DA was synthesized based on the procedure that has been described previously by Chiu et al. [23]. Briefly, $10 \mathrm{~g}$ of PEG $(\mathrm{Mw} \approx 8000)$ was lyophilized overnight and then placed into a three-neck round-bottom flask with $60 \mathrm{ml}$ of anhydrous dichloromethane. Two moles of triethylamine (TEA) per mole of PEG was added to the flask and stirred for $5 \mathrm{~min}$. Four moles of acryloyl chloride per mole of PEG were added dropwise to the flask and stirred for $24 \mathrm{~h}$. The resulting products were washed with 5 $\mathrm{ml}$ of $2 \mathrm{M} \mathrm{K}_{2} \mathrm{CO}_{3}$ and then precipitated in $2 \mathrm{~L}$ of ice-cold ethyl ether to separate residual acryloyl chloride.

The synthesis method for the PEG-PLLA copolymer was developed by Sawhney et al. [24]. Ten g of 
PEG and $2.12 \mathrm{~g}$ of 1-lactide were placed in a round-bottom flask and then $40 \mu \mathrm{L}$ of stannous octoate added as a catalyst. The entire flask was submerged in a heated oil bath $\left(140^{\circ} \mathrm{C}\right)$ to establish constant temperature conditions and the reaction was allowed to continue for $4 \mathrm{~h}$. The product was filtered through $42.5 \mathrm{~mm}$ glass microfiber filters and the copolymer was precipitated in ethyl ether. PEGPLLA was then acrylated as described above. PEG-DA and PEG-PLLA-DA were dissolved in chloroform-d to perform ${ }^{1} \mathrm{H}$ NMR (Advance $300 \mathrm{~Hz}$; Bruker) to evaluate the synthesized product.

\subsubsection{PLGA Microspheres Preparation}

A water-in-oil-in-water (w/o/w) double emulsion technique was used to produce PLGA microspheres [25]. The microspheres were loaded with PDGF-BB and used as the source in the gradient layer. Four different conditions were investigated $\left(0,1,10\right.$ and $100 \mu \mathrm{g} \mathrm{ml}^{-1}$ PDGF-BB). Briefly, $250 \mathrm{mg}$ of PLGA 50:50 was dissolved in $1 \mathrm{ml}$ dichloromethane (oil phase) with $7.5 \mathrm{mg} \mathrm{Mg}(\mathrm{OH})_{2}$. PDGF-BB and protein stabilizers (sucrose, BSA and PEG 8000) were dissolved in $0.2 \mathrm{ml}$ of PBS to form water phase then emulsified with oil phase. Water-oil emulsion was combined with $2 \%$ PVA (10 ml) to produce a second emulsion. Microspheres were collected by centrifugation, lyophilized and stored at $-80^{\circ} \mathrm{C}$.

\subsubsection{Gradient Scaffold Preparation}

PEG-fibrin composite hydrogels were prepared as described previously [26]. PEG-DA (250 mg $\mathrm{ml}^{-1}$ ) was dissolved in saturated salt water containing $\mathrm{Tb}\left(100 \mathrm{U} \mathrm{ml}^{-1}\right)$ and Irgacure $1173(0.5 \% \mathrm{w} / \mathrm{v}$, photoinitiator) to form the hydrogel precursor. Two hundred microliters of the precursor was mixed with $400 \mathrm{mg}$ of sieved salt crystals (300-500 $\mu \mathrm{m}$ in diameter) and polymerized under UV light (365 $\mathrm{nm}$ ) for 5 minutes. The salt crystals were then leached out in $50 \mathrm{ml}$ of DI water with agitation for 3 hours, and replacement of deionized (DI) water every hour. 
To generate gradients within the materials, multilayer structures were generated in which PLGA microspheres were placed at the distal end of the hydrogels within a thin, degradable hydrogel layer (Figure 1). PEG-PLLA-DA (100 $\left.\mathrm{mg} \mathrm{ml}^{-1}\right)$ was prepared in DI water and Irgacure $1173(0.5 \% \mathrm{w} / \mathrm{v}$, photoinitiator) was added to form the hydrogel precursor. Fifty microliters of the precursor was mixed with $15 \mathrm{mg}$ of PLGA microspheres and applied to the top of PEG-DA hydrogel using a thin spatula. Polymerization was carried out under UV light $(365 \mathrm{~nm})$ for 5 minutes. Next, the gel was placed in polypropylene shells (top hats) to orient the PLGA layer as distal to surrounding liquid/tissue. Excessive water was removed by blotting the hydrogels with sterile gauze, and the hydrogels were airdried for 1 hour to allow further evaporation of water from the pores. Three hundred microliters of a Fibrinogen $(\mathrm{Fg})$ solution (40 $\mathrm{mg} \mathrm{ml}^{-1}$ in saline) was added drop-wise into the pores of the hydrogel. Then, the gel was incubated at room temperature for $30 \mathrm{~min}$ to allow interaction of $\mathrm{Fg}$ with $\mathrm{Tb}$ to form the fibrin.

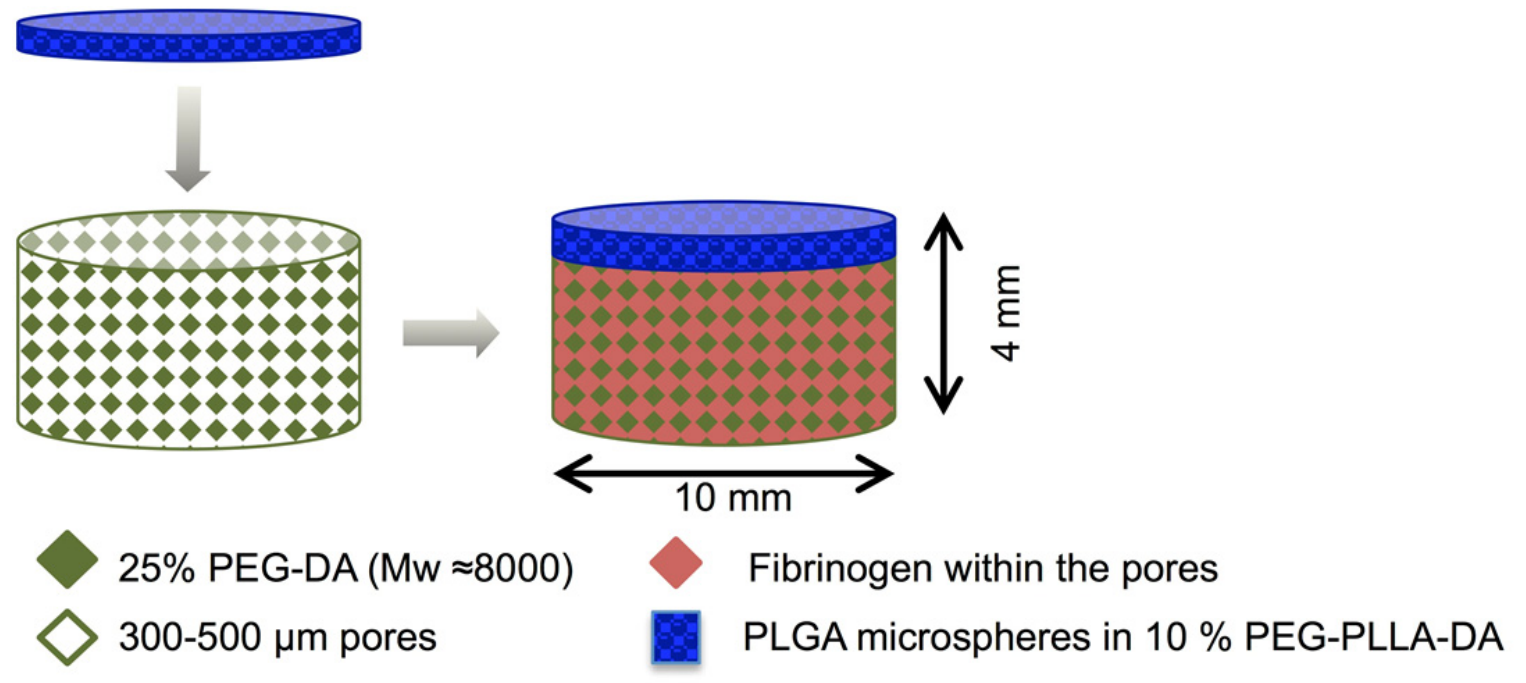

Figure 1. Schematic of the gradient scaffold preparation process. Porous PEG hydrogels containing thrombin are generated with a salt leaching method and then a PEG-PLLA layer containing PLGA microspheres is formed on the surface of the hydrogel scaffolds. Fibrinogen is then loaded into the pores where it is polymerized into fibrin. 


\subsubsection{Scaffold Fabrication with Homogenous Distribution}

Scaffolds with an initial homogeneous distribution of PDGF-BB throughout the hydrogel were used for comparison to the gradient scaffolds. Homogeneous scaffolds were prepared under two conditions. PLGA microspheres with 200 ng PDGF-BB were prepared as described in section 2.2.2, and the PEGDA hydrogel precursor was prepared as explained above. Two hundred microliters of the precursor and $400 \mathrm{mg}$ of sieved salt crystals $(300-500 \mu \mathrm{m}$ in diameter) were mixed with $15 \mathrm{mg}$ PLGA microspheres then polymerized under UV light $(365 \mathrm{~nm})$ for 5 minutes. The salt crystals were leached out in $50 \mathrm{ml}$ of deionized water with agitation for 3 hours, and replacement of deionized water every hour. Fibrinogen was loaded as explained above. A second method was performed by loading PDGFBB with fibrinogen into pores. Porous PEG-DA hydrogels were prepared without adding PLGA microspheres. PDGF-BB (200 ng) and heparin $\left(10 \mathrm{U} \mathrm{ml}^{-1}\right)$ were mixed with fibrinogen prior to addition to the pore [27]. The hydrogels were incubated at room temperature for $30 \mathrm{~min}$ to allow fibrin formation.

\subsection{Imaging of the Scaffold Structure}

Scaffold structure was visualized using confocal microscopy (Carl Zeiss AG, Germany). PLGA microspheres were labeled with $0.1 \%$ PKH-26 fluorescent dyes and the fibrinogen solution was mixed with $0.1 \mathrm{mg} \mathrm{ml}^{-1}$ of Fg conjugated with Alexa Fluor 647. PEG-DA was doped with PEG-PLLA-DA due to its auto-fluorescence [28]. The gel was prepared as discussed in Section 2.2.3. Microscopy conditions were set as following: PLGA microspheres (543 nm excitation, $560 \mathrm{~nm}$ long-pass filter), fibrin (633 nm excitation, $650 \mathrm{~nm}$ long-pass filter) and the hydrogel scaffold (488 $\mathrm{nm}$ excitation, 505$530 \mathrm{~nm}$ band-pass filter) with a 20x objective.

Furthermore, confocal microscopy was used to evaluate the porosity of the scaffold. Porosity $\left(\varepsilon_{t}\right)$ was 
determined by dividing the total pore volume by the total scaffold volume.

\subsection{Release Kinetics}

PDGF-BB (carrier free) was radiolabeled with iodine-125 $\left({ }^{125} \mathrm{I}\right)[29] .{ }^{125} \mathrm{I}-\mathrm{PDGF}-\mathrm{BB}\left(10 \mu \mathrm{g} \mathrm{ml}{ }^{-1}\right)$ was encapsulated in PLGA microspheres and three different groups were investigated: free PLGA microspheres, the top layer of the gradient scaffold (i.e. PLGA microspheres in the degradable polymer) and the full gradient scaffold ( $n=3$ samples per group). Emitted gamma radiation of the samples was measured with a $\Upsilon$ counter (Packard Instrument, Meriden, CT) prior to incubation to determine the total radiation data at day 0 . Gradient scaffold and top layer groups were placed in the same polypropylene shells described in the animal studies and incubated in $2 \mathrm{ml}$ of PBS in a 12-well trans-well plate at $37^{\circ} \mathrm{C}$. PBS was collected at each time point and emitted gamma radiation in the release samples measured. PBS was refreshed after each measurement and each measurement was added to previous measurements to generate cumulative release. Data were corrected for radioactive decay at each time point. Percent cumulative release profile was generated by dividing cumulative radiation data by the total radiation data of the samples.

\subsection{Diffusion Modeling}

Protein transport through the porous hydrogel was modeled in MATLAB ${ }^{\circledR}$ based on solving onedimensional Fick's Second Law:

$$
\frac{\partial C}{\partial t}=D_{e} \frac{\partial^{2} C}{\partial z^{2}}
$$

In Equation (1), $\mathrm{D}_{\mathrm{e}}$ is the effective diffusion coefficient $\left(\mathrm{cm}^{2} \mathrm{~s}^{-1}\right), \mathrm{z}$ is vertical distance $(0 \leq \mathrm{z} \leq 0.4 \mathrm{~cm})$, $\mathrm{t}$ is the time (s), and $\mathrm{C}_{\mathrm{i}}$ is the concentration $\left(\mathrm{g} \mathrm{ml}^{-1}\right)$. The model has the following assumptions: diffusion is the only mechanism of transport and concentration does not vary in the radial direction. 
Data from the release experiments was converted to flux and used to define the boundary condition in the distal end of the hydrogel, and the surrounding tissue was modeled as an infinite sink (i.e. $C_{i}=0$ ).

The diffusion coefficient of PDGF-BB (Mw $25 \mathrm{kDa})$ in an aqueous environment was reported as 1.08 $\mathrm{x} 10^{-6}\left(\mathrm{~cm}^{2} \mathrm{~s}^{-1}\right)$ by Lawrence et al. [30] and Xu et al. [31]. It is well-known that PEG does not allow protein adsorption [32,33], and PDGF-BB has a low affinity for fibrin within the porous structure [34,35]. Based on this information, we assumed that PDGF-BB did not interact with the scaffold. The effective diffusion coefficient within the scaffold was determined by fitting the model to experimental results in order to account for both steric effects of the scaffold structure and any binding to fibrin.

\subsection{Animal Model}

Animal experiments were performed at Edward Hines, Jr. VA Hospital and the Illinois Institute of Technology with procedures accepted by the Institutional Animal Care and Use Committee (IACUC2014-006). A rodent subcutaneous implantation model was used to evaluate tissue ingrowth into the material [26]. In this model, scaffolds were placed in polypropylene shells in the shape of a top hat (height $=4 \mathrm{~mm}$, diameter $=10 \mathrm{~mm}$, extended ring of $12 \mathrm{~mm}$ for suturing to the underlying tissue).

The scaffolds in the shells were implanted subcutaneously under the dorsal skin of male Lewis rats (300-400 g, Charles River) with the hydrogel surface in contact with the underlying skeletal muscle.

\subsection{Visualization of In Vitro and In Vivo Gradient within the Scaffold}

In order to visualize gradients of soluble factors within the scaffolds, BSA was first used as the model protein to refine the method. Studies of growth factor distribution in vitro and in vivo were performed with both BSA and PDGF-BB. BSA was labeled with ICG fluorescent dye (1:1 mole ratio). BSA and ICG were mixed in PBS and encapsulated into PLGA microspheres prepared with the double emulsion 
method. PDGF-BB was labeled with IRDye $800 \mathrm{CW}$ (infrared dye) according to manufacturer instructions. Briefly, $100 \mu \mathrm{g}$ of PDGF-BB was dissolved in $1 \mathrm{ml} \mathrm{PBS}$ and pH was brought to 9 using 1 M Potassium Phosphate buffer. The dye in ultra pure water $(5.18 \mu \mathrm{l})$ was mixed with protein and reacted for 2 hours in the dark. Free dye was separated from the protein using desalting spin columns. After labeling, the protein conjugate was encapsulated in PLGA microspheres using the standard procedures. Gradient scaffolds were prepared with protein conjugates for imaging in vitro and in vivo.

Scaffolds containing labeled proteins were placed in 12 well plates with $2 \mathrm{ml}$ PBS and incubated at $37^{\circ} \mathrm{C}$. The PBS was refreshed daily and samples were kept in the polypropylene shells to have consistent conditions between in vitro and in vivo studies. Hydrogels containing either ICG-labeled BSA (125 $\left.\mathrm{mg} \mathrm{ml}^{-1}\right)$ or IRDye 800-labeled PDGF-BB $\left(100 \mu \mathrm{g} \mathrm{ml}^{-1}\right)$ were implanted subcutaneously as described above. Scaffolds were imaged at day 1, week 1 and week 3. In vitro samples were imaged in well plates. Animals were sacrificed at each time point and sutures on the back of the rats were opened until a clear view of implants on the muscle was obtained. Since scaffolds were attached to muscle, top hats were removed as well. Then, animals were placed in the imaging drawer of the system.

Images were acquired in vitro and in vivo using a planar fluorescence-imaging device (Pearl ${ }^{\circledR}$ Impulse, LI-COR Biosciences, Lincoln, NE). The spatial resolution of the imaging system was set to $85 \mu \mathrm{m}$. At each time point, a white light image and a fluorescence image (800 nm emission wavelength) were acquired sequentially. Images were analyzed based on intensity of each pixel. Background signal was removed in the analysis. Intensity values were averaged in the radial direction (parallel to distal layer) to generate intensity profiles in the $\mathrm{z}$ direction (from distal layer to tissue bed).

\subsection{Evaluation of In Vivo Vascularization}

Four groups of sterile scaffold implants were prepared with varying growth factor concentrations $(0$ (control), 1, 10 and $100 \mu \mathrm{g} \mathrm{ml}^{-1}$ ) as described in Section 2.2.3. Loading concentrations were equal to 0 , 
2, 20 and $200 \mathrm{ng}$, respectively. Four implants were performed on each rat and implants were harvested at 1,3 and 6 weeks after implantation ( $\mathrm{n}=5$ for each time point). The highest dose (200 ng) was also evaluated at 4.5 weeks. Prior to harvest Alexa Fluor 647 conjugated isolectin (100 $\mu \mathrm{g})$ was injected into the tail vein, followed by perfusion fixation with $4 \%$ formaldehyde. Harvested samples were processed in two parts: half of the sample was paraffin-embedded and the other half frozen in optimal cutting temperature embedding medium. All samples were sectioned in the vertical direction so that each sample included an entire scaffold cross section from the distal layer to the underlying skeletal muscle.

An additional in vivo study was conducted to compare the effect of gradient scaffolds to scaffolds containing an initial homogeneous distribution of PDGF-BB. Four groups were evaluated in this study; Group 1: gradient scaffold without PDGF-BB (blank), Group 2: gradient scaffold with 200 ng PDGFBB, Group 3: scaffold with 200 ng PDGF-BB loaded PLGA microspheres homogenously distributed, Group 4: scaffolds with 200 ng PDGF-BB homogeneously distribution with the fibrin in the scaffold. Four implants were performed on each rat and implants were harvested at 1 week after implantation ( $n=3$ animals). Harvested samples were embedded in optimal cutting temperature and sectioned in the vertical direction for evaluation of tissue invasion as described below.

\subsubsection{Histology}

Paraffin-embedded sections (5 $\mu \mathrm{m}$ thickness) were stained with hematoxylin and eosin (H\&E) and Masson's trichrome. Hematoxylin and eosin (H\&E) staining was also performed on frozen sections (40 $\mu \mathrm{m})$ from the PDGF-BB distribution study. H\&E-stained sections were imaged to quantify tissue invasion using an Axiovert 200 inverted microscope (5x objective, $1.10 \mu \mathrm{m} / \mathrm{pixel})$. The depth of tissue invasion was quantified as the straight-line distance from the underlying muscle to the deepest location where tissue could be identified within the pores. Three measurements were taken and averaged for 
each section. For comparisons between paraffin embedded and frozen sections, shrinkage was accounted for based on relative gel height. In addition, Masson's trichrome-stained sections were used to visualize collagen structure and inflammatory response within the pores. The percentage of area stained positive for collagen in Masson's trichrome images was determined by selecting collagen areas and dividing by the total tissue area within the pores. Three images were taken per slides and five slides were imaged (10x objective, $0.53 \mu \mathrm{m} / \mathrm{pixel})$ per condition.

\subsubsection{Vascular Analysis}

Frozen tissue sections (50 $\mu \mathrm{m}$ thickness) were imaged with confocal microscopy (Carl Zeiss AG, Germany). The samples were imaged (20x objective, $0.88 \mu \mathrm{m} / \mathrm{pixel}$ ) for the Alexa Fluor 647 conjugated isolectin (633 nm excitation, $650 \mathrm{~nm} 310$ long-pass filter, far red) and background tissue autofluorescence 311 (488 nm excitation, 505-530 nm band-pass filter, green). Blood vessel density was quantified as the area of isolectin positive vessels divided by the total area of the tissue. Immunohistochemical staining for CD-31 and $\alpha$-SMA were also performed on paraffin embedded sections (5 $\mu \mathrm{m}$ thickness) as described previously [27]. Three images were taken per slides and five slides were imaged (20x objective, $0.27 \mu \mathrm{m} /$ pixel) per condition. Blood vessel density was analyzed by counting the number of CD-31 or $\alpha$-SMA positive vessels in each image. The number of positive stained vessels per area and the ratio of $\alpha$-SMA to CD-31 stained vessels were quantified.

\subsection{Statistical Analysis}

All statistical data are shown as mean \pm standard deviation. Paired Student's t-tests were used for comparisons of in vivo data. Growth factor release in vitro studies were analyzed with one-way repeated measures ANOVA using SigmaStat (San Jose, Ca). For all comparisons, p $<0.05$ was considered statistically significant. 


\section{Results and Discussion}

\subsection{Structure of the Gradient Scaffold}

A two-layer scaffold system was prepared in order to enable gradient formation within the bulk polymer. The system consisted of two biomaterial regions: a thick region consisting of a fibrin loaded porous PEG scaffold $(3.7 \mathrm{~mm})$ and a thin $(0.3 \mathrm{~mm})$ layer of PEG-PLLA hydrogel containing PLGA microspheres to serve as the source of the growth factors (Figure 2). A copolymer (PEG-PLLA) that degrades rapidly via hydrolysis was chosen to minimize resistance to PDGF-BB transport in the top layer. A non-degradable polymer (PEG) was used for the bulk scaffold to allow for formation of a long-lasting system upon implantation and to minimize the influence of changes in polymer properties on in vivo performance. A schematic representation and macroscopic image of the scaffolds are provided in Figure 2. The structure was evaluated using confocal microscopy (Figure 2C). Fluorescently tagged PLGA microspheres (blue) are present in the top layer of the scaffold. The microspheres were only present in the top layer suggesting that they did not leak into the bulk scaffold structure, which is essential for control over gradient formation. Fibrin (red) is included as it increases vascularization within the hydrogel [26] and can be observed throughout the pores (green) and at the interface with the top layer suggesting that fibrin was loaded throughout the scaffold volume. Sectioning artifact likely results in some pores appearing empty in the image as we have previously shown that fibrin loading results in distribution throughout the $4 \mathrm{~mm}$ depth of porous PEG-DA hydrogel at an incorporation efficiency of $79.9 \pm 2.6 \%$ [26]. The pore size of the scaffold was in 300 $500 \mu \mathrm{m}$ range and the porosity available for transport $\left(\varepsilon_{\mathrm{t}}\right)$ was calculated $(0.64 \pm 0.028)$. 




Figure 2. Formation of multilayer scaffold system. (A) Schematic representation of the gradient scaffold. (B) Gross image of the gradient scaffold. (C) Confocal image of a vertical section of the gradient scaffold indicating presence of the distal layer containing the PLGA microspheres (blue), underlying porous scaffold structure (green) and fibrin (red) loaded within the pores. Scale bar is 100 $\mu \mathrm{m}$.

\subsection{Release of PDGF-BB}

PDGF-BB, a protein known to stimulate the directed migration and growth of many cell types involved in tissue development and angiogenesis, was loaded in the PLGA microspheres. In the absence of a scaffold, free microspheres exhibited a burst release of $\sim 30 \%$ of PDGF-BB in the first four days followed by slower, continuous release for more than 6 weeks (Figure S1A). When microspheres were suspended in the thin layer of $10 \%(\mathrm{w} / \mathrm{v})$ PEG-PLLA, release was delayed (Figure S1A). Within the PEG-PLLA (top layer) group the release kinetics exhibited an initial burst $\sim 30 \%$ in the first four days similar to the free microsphere condition and a secondary burst of $\sim 10 \%$ between $15-18$ days, likely resulting when the hydrogel reaches complete degradation or its reverse gelation point. The release kinetics of the growth factor was altered by being physically entrapped in the PEG-PLLA hydrogel layer. Other PEG-PLLA conditions were examined. At higher concentrations release was delayed even further due to the slower degradation of the hydrogel (Figure S1B). For subsequent studies, the 10\% concentration was selected for the top layer of the gradient scaffold system due to the relatively fast release profile allowing for early establishment of a gradient within the bulk scaffold. 
The combination of the PLGA microsphere-containing degradable hydrogel layer with the porous PEG scaffold results in a further delay in release due to the diffusive resistance of the gel (Figure S1A). The gradient scaffold system showed a burst release in the first four days, at a level $(\sim 20 \%)$ lower than the burst exhibited from free PLGA microspheres and top layer (PLGA and PEG-PLLA). In the gradient scaffold, the secondary burst release $(\sim 10 \%)$ was observed at $\sim 15$ days coinciding with complete degradation of the top layer. Overall PDGF-BB was released from the hydrogel system for 6 weeks suggesting that the presence of PDGF-BB could be sustained within the hydrogel for times relevant to many biological processes. Release continued in all groups continued passed 6 weeks at low levels, but without a statistically significant difference between conditions (i.e. no difference in the ultimate plateau level of release).

\subsection{Diffusion Modeling of Gradient Scaffold System}

Varying levels of PDGF-BB were loaded in the system $\left(1,10\right.$ and $\left.100 \mu \mathrm{g} \mathrm{ml}^{-1}\right)$ in order to investigate the influence of PDGF-BB dose on gradient characteristics. These concentrations correspond to doses of 2, 20 and $200 \mathrm{ng}$, respectively. As a first step in evaluating the scaffolds a model of diffusive transport was used to approximate the spatial distribution of PDGF-BB within the scaffolds. Spatial (z direction) and temporal variations in PDGF-BB concentration assuming that diffusion was the mechanism of transport within the scaffolds are shown in Figure 3. The maximum concentration occurs at the interface with the top layer containing the PLGA microspheres $(z=0)$ with a gradient in concentration to the tissue-scaffold interface $(z=4 \mathrm{~mm})$. The general shape of the concentration profile was the same for all cases. However, absolute concentration varied with dose.

At all doses, concentration decreased steadily from 0-20 days followed by a slight increase at 20 days due to the secondary release from the top layer. Previous studies found that the minimum PDGF$\mathrm{BB}$ concentration required for cell activation is on the order of $1 \mathrm{ng} \mathrm{ml}^{-1}[36,37]$. At the highest PDGF- 
BB dose (200 ng), the concentration within the gradient hydrogel remains above this threshold for $\sim 5$ weeks.

The influence of PDGF-BB on cell behavior is a function of both absolute concentration and gradient magnitude [31,38]. Multiple cell types (endothelial cells, mural cells, fibroblasts etc.) are involved in the vascularization and tissue remodeling. We used previous studies of the response of various cells to gradients in vitro to provide insight into potential optimal gradients for vascularization in vivo [31,38-40]. The cell size and optimal concentration values will depend on the cell type and tissue location. These differences may change that actual values identified but not the overall approach used. The targets discussed here provide insight into possible targeted values but further studies are required to fully understand the complicated in vivo process. At saturating concentrations of PDGF-BB $\left(>10 \mathrm{nM}, 250 \mathrm{ng} \mathrm{ml}^{-1}\right)$ cells are unable to sense gradients due to the lack of signaling polarity within the cell. In our system the PDGF-BB concentration does not reach saturation level even at the highest dose. Below saturation levels gradients can be sensed by cells leading to distinct functional outcomes [38]. The gradient, $\delta$, a cell is exposed to can be defined in Equation (2):

$$
\delta=\frac{C_{i}(\text { front })-C_{i}(\text { back })}{C_{i, a v g}} ; C_{i}, a v g=\frac{C_{i}(\text { front })+C_{i}(\text { back })}{2}
$$

where front and back indicate the front and back of the cell relative to the gradient. We considered an elongated cell to have a length $\left(\mathrm{L}_{\text {cell }}\right)$ of $\sim 50 \mu \mathrm{m}(0.05 \mathrm{~mm})$. In this case the relative gradient experienced by a cell at any location, z (mm), within our scaffold can be estimated by Equation (3):

$\delta_{g e l}=\frac{C_{i}(z)-C_{i}(z-0.05)}{C_{i, a v g}} ; \quad C_{i}, \operatorname{avg}=\frac{C_{i}(z)+C_{i}(z-0.05)}{2}$

PDGF-BB gradients have the most significant effect at average concentrations $\left(C_{i, \text { avg }}>2.5 \mathrm{ng} \mathrm{ml}^{-1}\right)$ and high gradient magnitudes $\left(\delta_{\text {gel }}>0.3\right)$. These conditions result in differences in enzyme recruitment 
between the front and back of the cells and maximize cell migration speed [38]. Based on these values the minimum gradient $\left(\frac{\partial C_{i}}{\partial z_{\text {min }}}\right)$ at any location within our hydrogel expected to have a significant effect as shown in Equation (4):

$$
\frac{\partial C_{i}}{\partial z_{\min }}>\frac{\delta_{g e l^{*}} C_{i, a v g}}{L_{\text {cell }}}>\frac{0.3 * 2.5 \mathrm{ngml}^{-1}}{0.05 \mathrm{~mm}}>15 \mathrm{ngml}^{-1} \mathrm{~mm}^{-1}
$$

When examining the material-tissue interface (Figure 3D), we can see that at the highest PDGF-BB dose $(200 \mathrm{ng})$ the minimum gradient is achieved for over 4 weeks. The intermediate dose (20 ng) achieves this level for just over 1 week and the lower dose does not reach this threshold. Overall, at $200 \mathrm{ng}$ PDGF-BB dose the conditions for optimal gradient effect $\left(\mathrm{C}_{\mathrm{i}}>2.5 \mathrm{ng} \mathrm{ml}^{-1}\right.$ and $\left(\frac{\partial C_{i}}{\partial z_{\min }}\right)>15 \mathrm{ng}$ $\mathrm{ml}^{-1} \mathrm{~mm}^{-1}$ ) are present for over 4 weeks throughout the entire scaffold volume. 

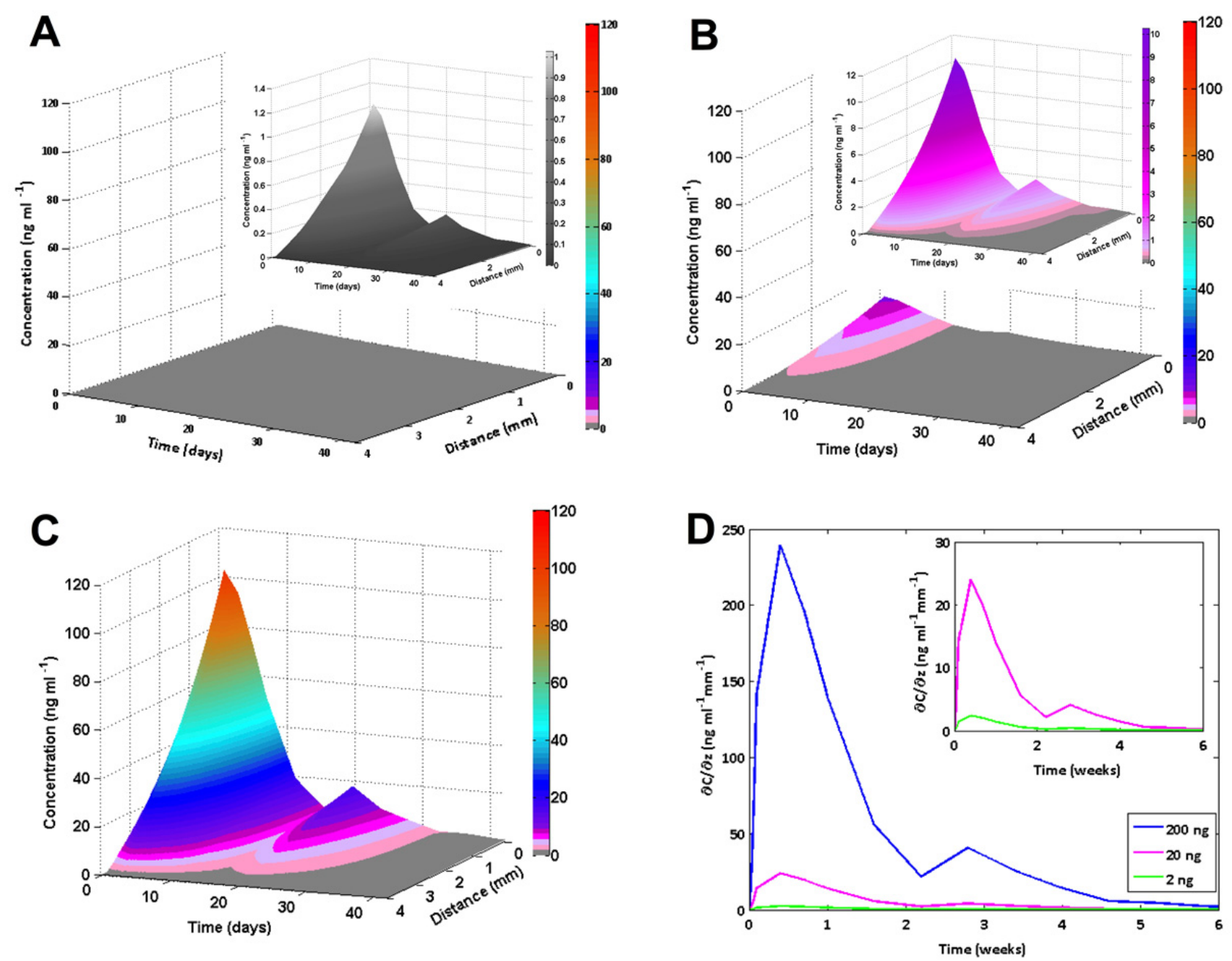

Figure 3. Concentration profiles within gradient scaffold systems from a diffusion model simulation. (A) (B) (C) Concentration profiles within the scaffold with PLGA microspheres loaded different doses of PDGF-BB (2, 20, $200 \mathrm{ng}$ for A, B and C, respectively) predicted from a diffusion model. The color bar is in units of $\mathrm{ng} \mathrm{ml}^{-1}$ and is constant for all images. Insets show concentration distributions at higher scale. All systems result in the same profile shape but different magnitude. Location $(\mathrm{z}=0)$ is the distal-gradient layer of the scaffold and distance $(\mathrm{z}=4 \mathrm{~mm})$ is the scaffold-tissue interface. (D) Magnitude of the gradient for all cases $(1,10$ and $100 \mathrm{ug} / \mathrm{ml})$ at the tissue interface. The inset shows 2 and $20 \mathrm{ng}$ cases at a higher scale.

\subsection{Verification of Gradients in the Scaffold System}

Results from the transport model provide insight into the possible distribution of PDGF-BB within the scaffold. The spatial distribution of proteins within the scaffolds was then verified via imaging in vitro and in vivo. Proteins were labeled with a fluorescent molecule to allow visualization of growth factor 
distribution with a planar near infrared fluorescence imaging system. First, a model protein (BSA) labeled with ICG was used to compare in vitro and in vivo distributions. The protein was observed within the hydrogels in vitro and in vivo (Figure 4A). The PLGA source exhibited a high signal with fluorescence intensity decreasing from the distal region to the tissue bed in vivo (Figure 4B). Intensity showed little variation in the radial direction suggesting that edge effects of the chamber were minimal and the system could be largely considered to have variation in concentration primarily in the axial (z) direction.

The distribution of the fluorescently labeled protein in vivo can be clearly seen at 1 week (Figure 4C). Intensity within the scaffolds was quantified in vitro and in vivo at day 1, week 1 and week 3 (Figure 4D). When comparing in vitro and in vivo results the profiles were similar. At the tissue-biomaterial interface, fluorescence data approached background levels. Intensity was slightly higher at the distal end for in vivo relative to in vitro for all time points. The higher values for in vivo samples may be due to the close adherence of the polypropylene shells to the muscle relative to the bath used for incubation in vitro. The bath serves as an effective sink, while the diffusive resistance present in the muscle may result in an elevated concentration at the boundary. The in vitro samples were floating in well plates resulting in more movement within the shells. In addition, in vitro samples required more handling during imaging, which may also cause deviations from in vivo data. 

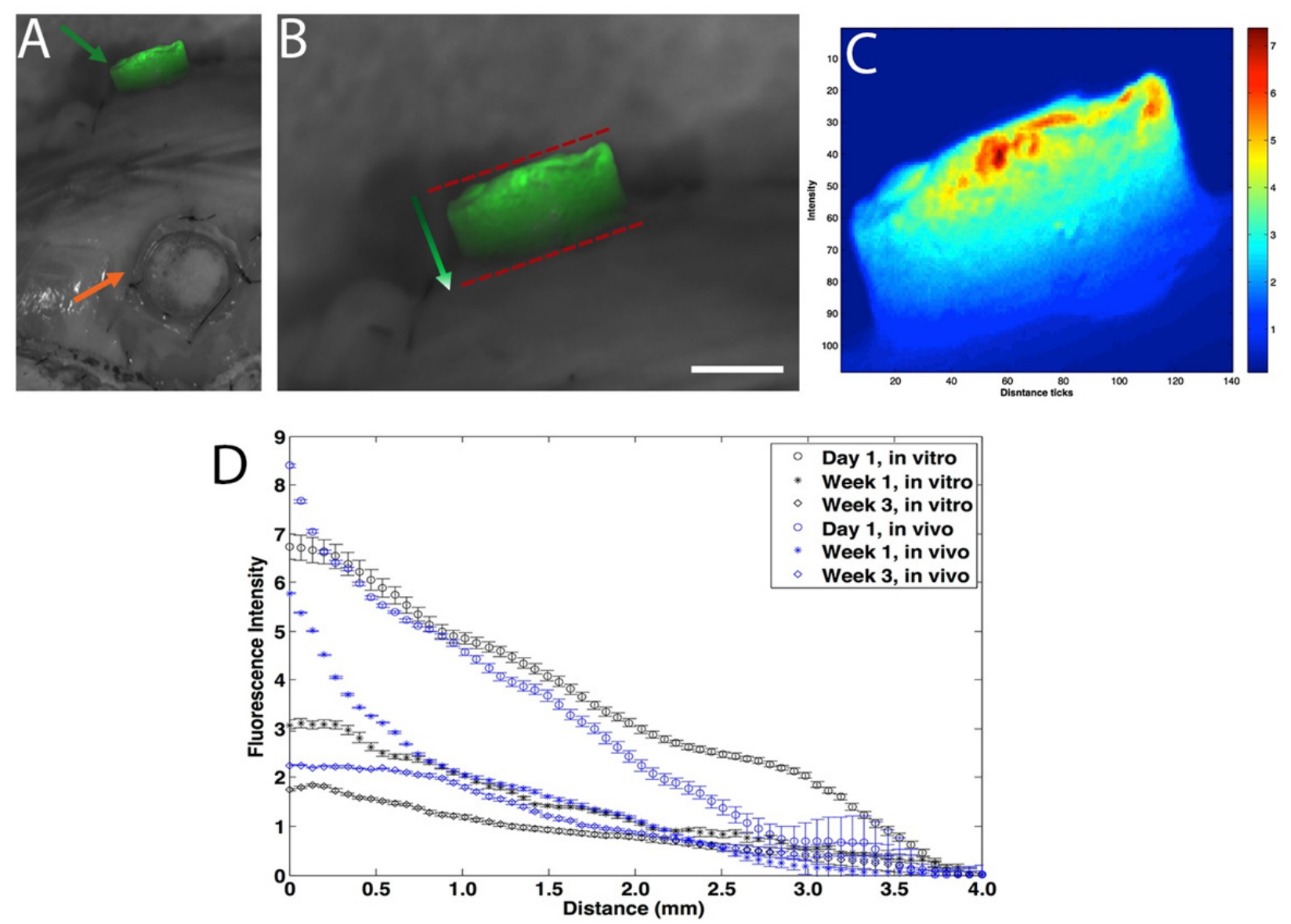

Figure 4. Multilayer systems result in gradients of soluble factors in vivo. (A) In vivo imaging of concentration distribution of BSA within the scaffold at 1 week. Green arrow indicates the scaffold with ICG-BSA and the orange arrow indicates the control scaffold with non-labeled BSA. (B) Zoomed in image of the scaffold with ICG-BSA with red dotted lines indicating the distal layer and tissue interface. The scale bar is $5 \mathrm{~mm}$. (C) $2 \mathrm{D}$ intensity profile of the scaffold shown in (B). (D) Fluorescence intensity profile in $\mathrm{z}$ direction (from distal layer to tissue interface) for in vivo (blue) and in vitro (black) experiment at day 1 , week 1 and week 3.

A fluorescent dye (IRDye 800) was conjugated to PDGF-BB, which was then incorporated into the PLGA microspheres within the scaffolds system. The scaffolds were then imaged after subcutaneous implantation at day 1, week 1 and week 3 (Figure 5). The distribution of the labeled growth factor could be clearly identified within the scaffold, with a gradient observed at all time points (Figure 5D). The intensity was highest at the distal region containing the PLGA microspheres and intensity values decreased to near zero at the tissue interface. These results suggest that the infinite sink boundary 
condition at the biomaterial-tissue interface used in the modeling studies was appropriate. The magnitude of the gradient decreased with time, but a gradient was still observed at 3 weeks. In addition, PDGF-BB gradient in vitro was evaluated. Gradient formation was verified in vitro and the trends were similar to in vivo results (Figure S2).

The in vivo experimental findings were compared to the predictions from the diffusion model (Figure 5E). Trends observed in the model predictions matched well with data obtained from the in vivo images particularly near the biomaterial-tissue interface. Some deviation was observed between model predictions and experimental results at the distal boundary. This may result from difficulty in precisely identifying the interface between the distal layer and scaffold surface during image analysis. 

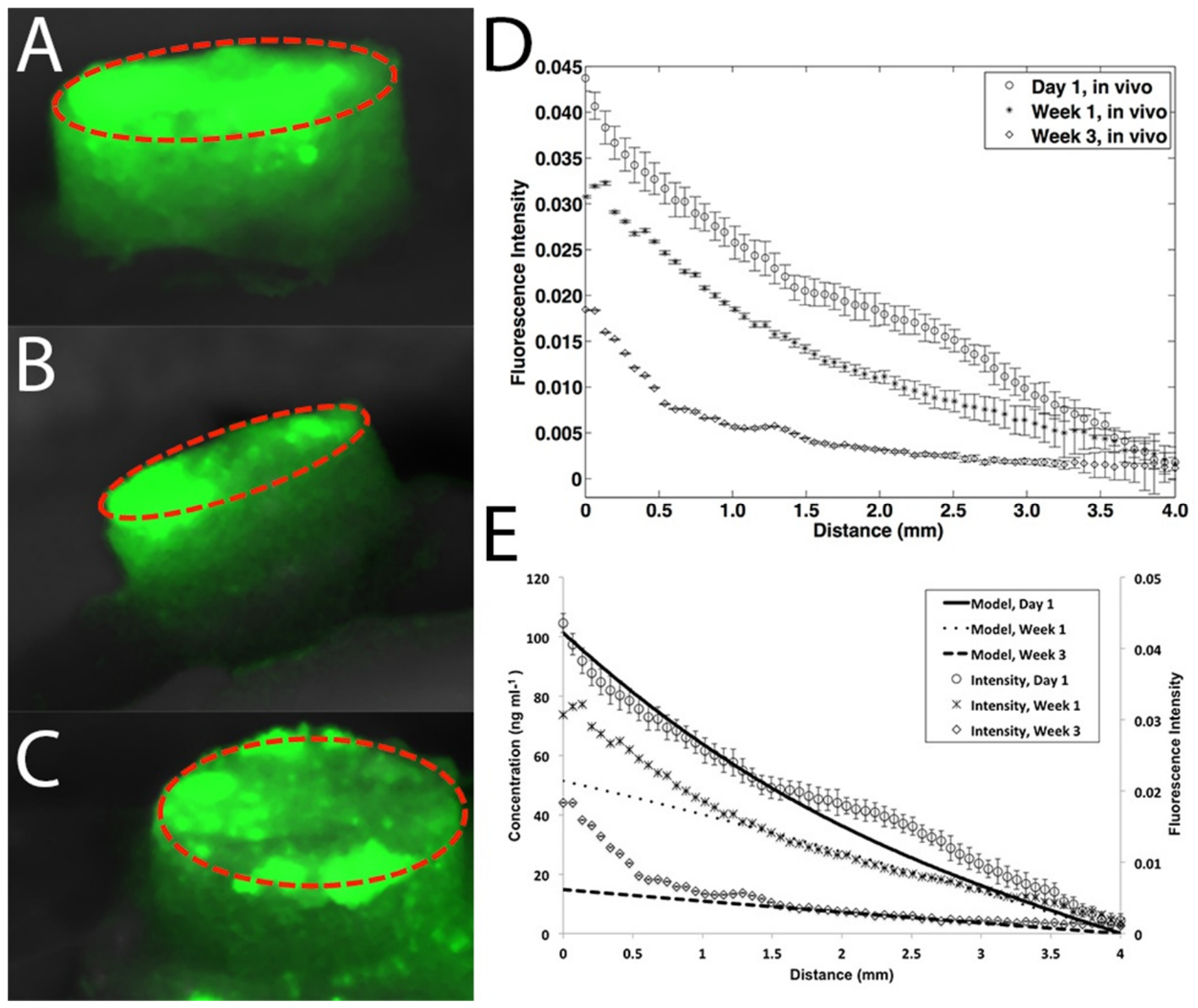

Figure 5. Gradients of PDGF-BB in hydrogel scaffolds in vivo. In vivo images of scaffolds prepared with $100 \mu \mathrm{g} / \mathrm{ml}$ IRDye 800 labeled PDGF-BB at day 1 (A), week 1 (B) and week 3 (C). Red dashed circles indicate the distal layer of the scaffold. (D) Fluorescence intensity of IRDye 800-PDGF-BB within the gel at day 1 , week 1 and week 3. (E) Comparison between model $(100 \mu \mathrm{g} / \mathrm{ml}$ PDGF-BB) and experimental results for PDGF-BB distribution in vivo. Concentration of PDGF-BB within the scaffold (ng $\mathrm{ml}^{-1}$ ) based on predictions from the diffusion model and experimental measurements (fluorescent intensity).

Significant research is ongoing on the impact of gradients of soluble factors on biological processes. However, the ability to generate gradients in vivo and verify them is crucial to understanding the characteristics of the gradient systems and analyzing the biological response. Imaging techniques are routinely used to analyze the distribution of labeled proteins in microfluidic systems $[31,39,41,42]$. Gradient biomaterial systems are popular candidates for tissue engineering applications, but gradient 
formation has only been evaluated in vitro $[18,19,43]$. In this system, the gradient distribution of a growth factor in a porous scaffold was imaged in vivo and persisted for over 3 weeks.

\subsection{Tissue Invasion}

Tissue invasion into the scaffolds was analyzed for 2, 20 and $200 \mathrm{ng}$ PDGF-BB doses. Greater tissue invasion occurred in gradient scaffolds loaded with 20 and 200 ng of PDGF-BB doses relative to the control group (0 ng PDGF-BB) at all time points (Figure 6A). The lowest gradient magnitude (2 ng) did not stimulate significantly greater tissue invasion than the control $(0 \mathrm{ng})$ at week 1 and week 6 but there was a statistical difference at week 3. All gradient hydrogel groups exhibited a higher depth of invasion in week 3 relative to week 1 . At week 1 and week 3 hydrogels with the highest PDGF-BB dose $(200 \mathrm{ng})$ showed the greatest tissue invasion depth $(1801 \pm 135 \mu \mathrm{m})$. The depth of tissue invasion decreased from 3 to 6 weeks. Further investigation of tissue growth for the $200 \mathrm{ng}$ dose was performed to gain insight into tissue ingrowth characteristics between 3 and 6 weeks. The maximum invasion depth $(2165 \pm 113 \mu \mathrm{m})$ was seen at 4.5 weeks (Figure $7 \mathrm{C})$. At the highest loading dose an average of eighty percent of the total gel volume was invaded by vascularized tissue at 4.5 weeks. Three out of 5 samples of this group showed vascularized tissue formation throughout the entire gel volume. Vascularization in existing tissue can occur at a relatively rapid rate due to the existence of cells, matrix and tunnels within the tissue [44]. However, ectopic generation of vascularized tissue is much slower due to the coordination of proliferation and migration of multiple cells, matrix production and cell assembly over a $4 \mathrm{~mm}$ scaffold thickness [45].

When comparing these results to the diffusion model, concentration dropped below $2.5 \mathrm{ng} \mathrm{ml}^{-1}$ around 5 weeks, suggesting that beyond this time point there is insufficient growth factor to promote tissue invasion and stabilization. As discussed in section 3.3, optimum gradient conditions were reported $\mathrm{C}_{\mathrm{i}}>$ 
$2.5 \mathrm{ng} \mathrm{ml}^{-1}$ and $\left(\frac{\partial C_{i}}{\partial z_{\min }}\right)>15 \mathrm{ng} \mathrm{ml}^{-1} \mathrm{~mm}^{-1}$. The middle dose (20 $\mathrm{ng}$ PDGF) is in these optimal conditions until week 3 when concentration values $\left(C_{i}\right)$ drops under $2.5 \mathrm{ng} \mathrm{ml}^{-1}$ and gradient values were under $5 \mathrm{ng} \mathrm{ml}^{-1} \mathrm{~mm}^{-1}$. These findings correlate with the tissue invasion trend of $20 \mathrm{ng}$ PDGF-BB hydrogels, which showed a significant increase between weeks 1 and week 3 and decreased after that. The predicted concentration of PDGF-BB at the highest dose (200 ng) dropped below $2.5 \mathrm{ng} \mathrm{ml}^{-1}$ around 5 weeks. Although relatively high concentration values were found at the initial time points, they never reached the saturation concentration $\left(250 \mathrm{ng} \mathrm{ml}^{-1}\right)$. Both concentration and gradient predictions (Figure 3C and D) stay in the optimum range between 4 and 5 weeks. These results support the findings that the maximum tissue invasion was found at 4.5 weeks. Histological images reveal the interconnected porous structure of the hydrogel with tissue generated within the pores (Figure 6C).

Evidence of inflammatory tissue was observed primarily at the leading edge of the tissue. The remainder of the tissue was remodeled into dense collagen with blood vessels present within the pores (Figure 6E). The percentage of collagen within the invaded tissue was quantified (Figure 6B and F). Collagen percentage did not change from week 1 to week 3 and then decreased from week 3 to week 6. Presence of gradient promoted collagen formation. Although collagen formation was seen in earlier and later time points (week 1, week 3 and week 6), collagen density appeared in the largest fraction of the gel in the 4.5 weeks samples (Figure 6F). 

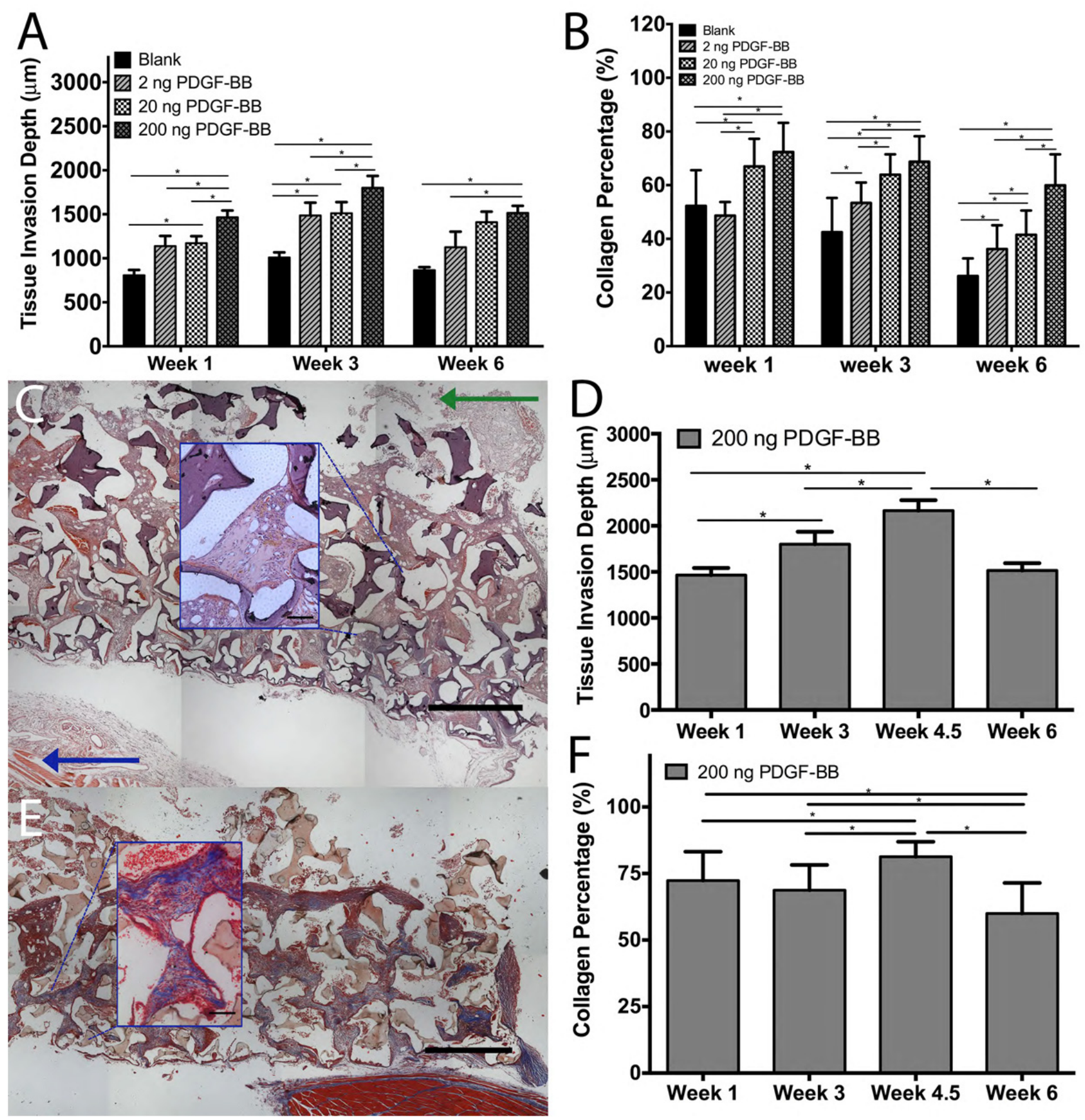

Figure 6. Tissue invasion and collagen density within the porous scaffold structure. (A) Invasion depth in the scaffolds (Blank, 2, 20 and $200 \mathrm{ng}$ ) at weeks 1, 3 and 6 measured from histological images of H\&E staining. (B) Collagen density in the scaffolds (Blank, 2, 20 and $200 \mathrm{ng}$ ) at weeks 1, 3 and 6 measured from histological images of Masson's Trichrome stains. (C) H\&E stained section showing tissue invasion within the porous hydrogel scaffolds, the distal layer (green arrow) and underlying skeletal muscle (blue arrow), scale bar is $1000 \mu \mathrm{m}$. (D) Invasion depth for gradient scaffolds with PLGA microspheres at $200 \mathrm{ng}$ was determined at additional time points (weeks 1, 3, 4.5 and 6) showing that maximum invasion was achieved at 4.5 weeks. (E) Masson's Trichrome stained section showing collagen formation within the porous hydrogel scaffold. Scale bar is $1000 \mu \mathrm{m}$. Scale bars in 
the insets are $100 \mu \mathrm{m}$. (F) Collagen density for gradient scaffolds with $200 \mathrm{ng}$ was determined at additional time points (weeks 1, 3, 4.5 and 6) showing that maximum collagen density was achieved at 4.5 weeks. ${ }^{*}$ Indicates $\mathrm{p}<0.05, \mathrm{n}=5$ samples per group.

The PDGF-BB dose used in the gradient system influenced tissue response. In this study PLGA microspheres were loaded with 1, 10, $100 \mu \mathrm{g} \mathrm{ml} \mathrm{m}^{-1}$ PDGF-BB corresponding to doses of 2, 20, and 200 ng. In a non-gradient system, $160 \mathrm{ng}$ of PDGF-BB was found to induce angiogenesis in a mouse corneal micropocket assay [37]. In a separate study $3 \mu \mathrm{g}$ of PDGF-BB delivered from PLGA scaffolds increased blood vessel maturation [22]. These studies suggest that the required dose depends on the biomaterial system and target environment. In this study we were able to show that PDGF-BB at even low doses (20 ng) was able to have a biologic effect when delivered as a persistent gradient. For future studies, our biomaterial design and developed imaging strategy can be used to investigate optimal gradient magnitudes for angiogenesis or other tissue engineering purposes.

\subsection{Vascularization in the Regenerated Tissue}

Blood vessels within the scaffolds were examined via lectin perfusion and imaged with confocal microscopy. Representative images from control and gradient hydrogels at week 1, 3 and 6 are shown in Figure 7. The gradient scaffolds (Figure 7D, H and L) exhibited a higher vascular density than the control group (Figure 8A, E and I). Gradient scaffolds showed a well-interconnected blood vessel network. Blood vessel size and density appeared higher at week 3 when comparing the gradient (Figure 8F-H) and control groups (Figure 7E).

Blood vessel density was quantified from the images (Figure $7 \mathrm{M}$ ). At week 1 gradient scaffolds displayed higher blood vessel density than the control group. In the control group vessel density decreased from week 1 to later time points (week 3 and 6). This likely results from an early inflammatory response and degradation of fibrin over time decreasing the angiogenic stimulus. At 
weeks 3 and 6, 20 and $200 \mathrm{ng}$ PDGF-BB scaffolds has a significantly higher vascular density than the control group. The percent blood vessel density for $20 \mathrm{ng}$ PDGF-BB was $(7.99 \pm 0.83,3.51 \pm 0.70)$ at 3 weeks and 6 weeks, respectively. The vascular density in $200 \mathrm{ng}$ PDGF-BB scaffolds was found $(12.05 \pm 2.51 \%, 8.98 \pm 1.41 \%)$ at 3 weeks and 6 weeks. The $200 \mathrm{ng}$ scaffold had the highest blood vessel density, which was significantly higher than other groups at all times. No difference was observed among other gradient groups (2 and 20 ng PDGF-BB). 


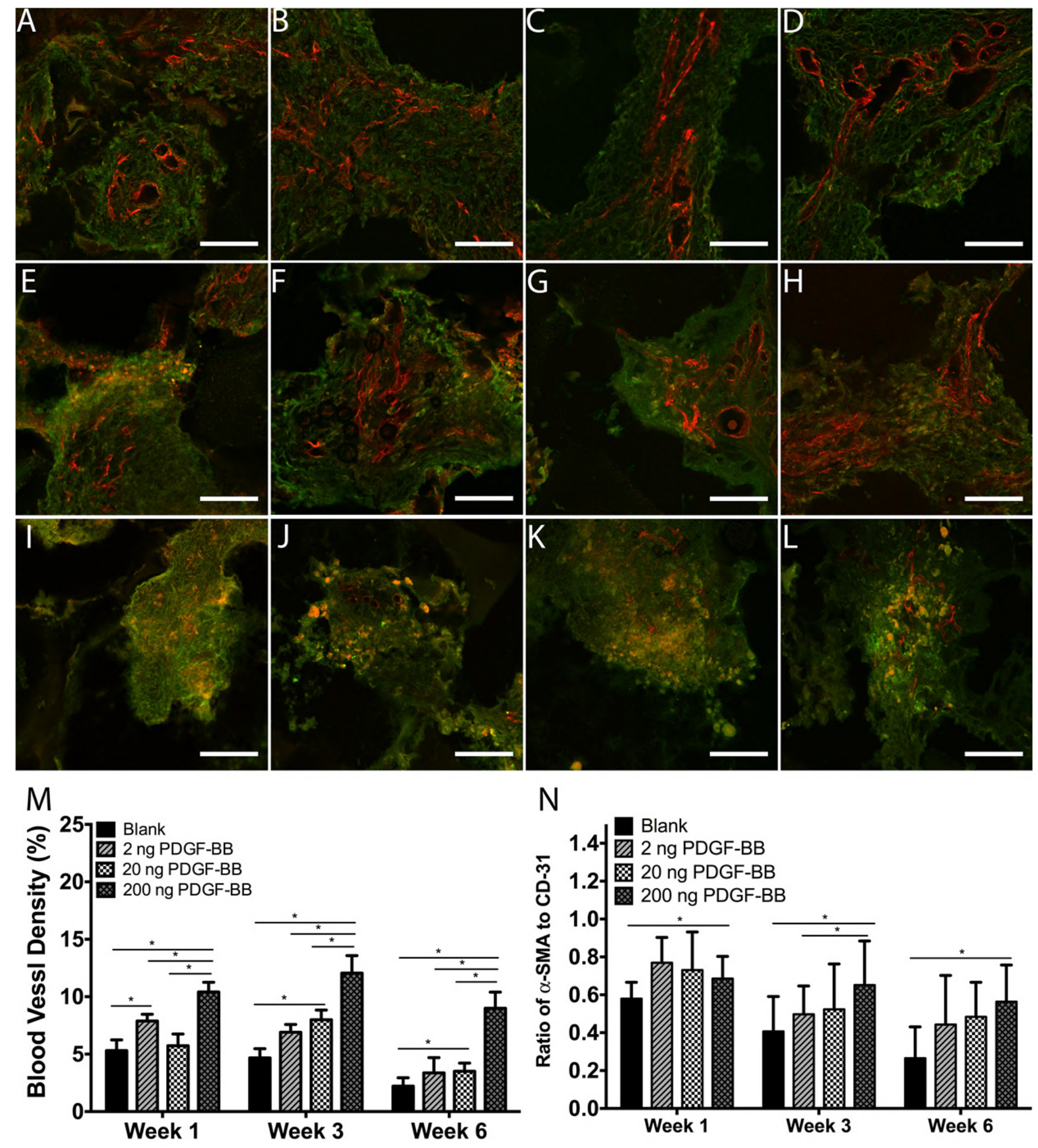

Figure 7. Vessel invasion within the scaffolds. (A-D) Week 1, (E-H) week 3 and (I-L) week 6 images of lectin perfused vessels for gradient scaffolds with 0 (A, E, I), 2 (B, F, J), 20 (C, G, K) and 200 (D, $\mathrm{H}, \mathrm{L}) \mathrm{ng} \mathrm{ml}^{-1}$ PDGF-BB. Red shows the isolectin labeled blood vessels and green is autofluorescence of the newly invading tissue. Scale bars are $100 \mu \mathrm{m}(\mathrm{M})$ Percent blood vessel density for blank and gradient scaffolds (2, 20 and $200 \mathrm{ng})$ at week 1, 3 and 6 was determined from the confocal images 
showing that density was maximal at the highest PDGF-BB dose. (N) The ratio of $\alpha$-SMA to CD-31 for blank and gradient scaffolds (2,20 and $200 \mathrm{ng}$ ) at weeks 1, 3 and 6 determined from immunohistochemical stains for CD-31 and $\alpha$-SMA. *Indicates $\mathrm{p}<0.05, \mathrm{n}=5$ samples per group.

Despite the higher blood vessel density seen in the gradient scaffolds, blood vessel density was lower for all groups in week 6 similar to what was observed in tissue invasion. Insufficient PDGF-BB gradient at these later time points may lead to a reduction in blood vessel density. The regression of regenerated tissue at week 6 might occur due to insufficient vasculature. In a pervious study [27] with PDGF-BB $\left(5 \mu \mathrm{g} \mathrm{ml}^{-1}\right)$ loaded microspheres homogeneously distributed in porous fibrin loaded scaffolds, maximum invasion depth was 1.5 times less than gradient scaffolds. Consequently, the presence of a gradient may increase vascularized tissue formation over homogeneous distribution.

Immunohistochemical staining for CD-31 was also performed to evaluate the overall formation of vessels including those that were not identified by lectin staining (i.e. vessels without flow). Mural cells were identified with staining for $\alpha$-SMA, which can be used as an indication of vessel maturity. Maximal vessel density for all groups was at week 1 (Figure S3A). This might be due to the early inflammatory response and maximum abundance of fibrin in the early time points. Although more CD31 positive vessels were seen in the gradient groups relative to controls, there were no statistical differences between the different gradient magnitudes at week 3. By week 6, vessel density had decreased but gradient scaffolds ( 2 and 200 ng PDGF-BB) remained higher than controls. For $\alpha$-SMA stains, week 1200 ng PDGF-BB had a greater density than other groups (Figure S3B). At week 3, all gradient groups had a higher density of of $\alpha$-SMA positive vessel in comparison to the control. The number of $\alpha$-SMA positive vessels decreased for all groups at week 6 with the number of positive vessels greater in the $200 \mathrm{ng}$ PDGF-BB group relative to the 20 ng PDGF-BB group. The ratio of $\alpha$ SMA positive vessels to CD-31 can be used as a measure of vessel maturity [46]. At weeks 1 and 6, the 200 ng PDGF-BB scaffold the ratio was significantly greater than the control (Figure 7N). 
In the previous sections we have provided a detailed description of the generation of persistent in vivo gradients of growth factors in a biomaterial system and the influence of gradient magnitude on tissue regeneration and vascularization. We next performed a study to evaluate the difference between gradient and homogeneous distribution of PDGF-BB in scaffold systems. Homogenous distributions were accomplished by either distributing PLGA microspheres within the scaffold structure or incorporating PDGF-BB directly into the fibrin present throughout the porous structure. Invasion of vascularized tissue was evaluated at 1 week (Figure 8). All PDGF-BB loaded scaffolds resulted in greater tissue invasion relative to blank scaffolds. However, the maximum depth of invasion was achieved in the gradient scaffolds $(1487.01 \mu \mathrm{m} \pm 219.18)$. The spatial distribution of growth factors within the scaffold plays an important role in vascularized tissue ingrowth.

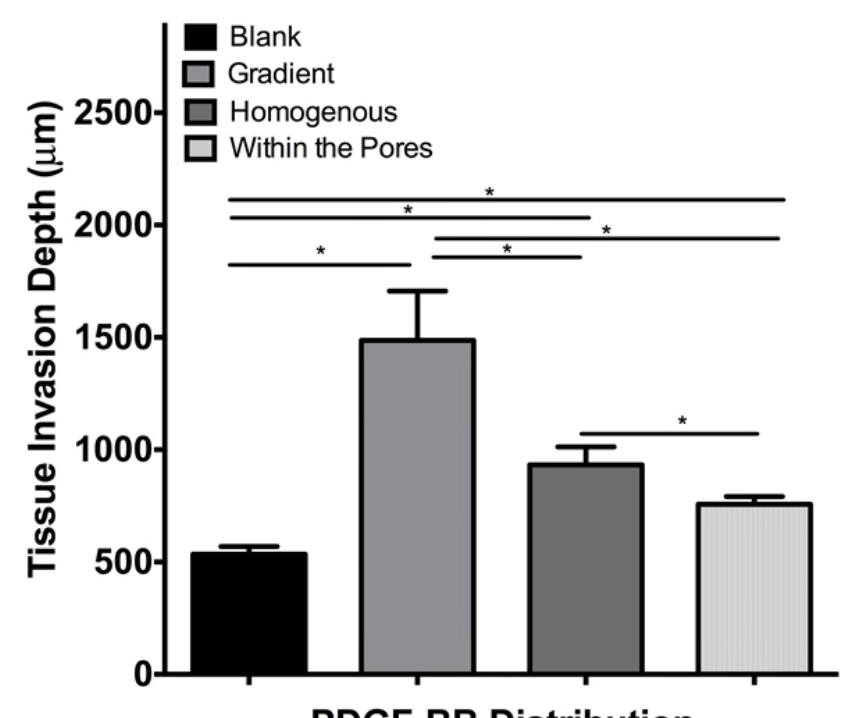

Figure 8. Tissue invasion depth within gradient and homogeneous scaffolds at week 1. Blank, gradient with $200 \mathrm{ng}$ PDGF-BB, homogenous scaffolds continuing PLGA microspheres loaded with $200 \mathrm{ng}$ PDGF-BB in the hydrogel structure and $200 \mathrm{ng}$ PDGF-BB in fibrinogen in the pores. Tissue invasion depth in the scaffolds was measured from histological images (H\&E). *Indicates $\mathrm{p}<0.05, \mathrm{n}=$ 3 samples per group.

A significant concern of our system is the tissue regression observed between weeks 4.5 and week 6 . This likely results from the drop in both concentration and gradient within the scaffolds. This issue could be addressed with a number of different strategies. Sequential or combination growth factor 
delivery may enhance the tissue and vessel stability [22,47-49]. FGF-1 (fibroblast growth factor) or VEGF (vascular endothelial growth factor) are strong angiogenic factors with higher affinity for fibrin. The incorporation of one or more of these factors to the fibrin network may allow for sequential delivery and enhanced vascularization [27]. The animal model used may limit the long-term stability of the tissue formed due to the absence of a tissue parenchyma. A mature tissue could result in parenchymal cells that establish an equilibrium balance with the vessels providing the signals required for maturation and stability. Under appropriate conditions, stem or progenitor cells seeded into scaffold may ultimately lead to this mature tissue. Further optimization of the physical properties of the scaffold may also enhance tissue formation. Pore interconnectivity can permit even greater tissue invasion and vascularization [50].

The gradient system described here could be applied in a broad range of applications in tissue engineering and regenerative medicine. While significant research has been performed in vitro using microfluidic systems to study gradients [14,39,51,52], little is known about the effects in multicellular processes in vivo. This system provides an environment in which gradients can be generated in vivo for study of angiogenesis, tissue development and many other processes. In addition, the ability to build highly vascularized scaffolds is critical to the generation of most tissues [53]. The slow and limited process of vascularized tissue development hinders the development of tissues of clinically relevant size [54]. This biomaterial system provides an approach that can further enhance the rate of vascularization. These systems my be particularly suitable when tissue is engineered in a clinically applied in vivo bioreactor model $[55,56]$ that mimics the largely one dimensional tissue invasion of the small animal model used here.

\section{Conclusions}

The overall goal of this research was to design a 3D scaffold system that allows for the formation of 
persistent gradients of soluble factors in vivo. Gradient formation was verified both in vitro and in vivo, and the presence of PDGF-BB gradients increased the depth of tissue invasion and density of blood vessels in a dose-dependent manner. The concentration of PDGF-BB and magnitude of the gradient fell within target levels for more than 3 weeks. In conclusion, this system provides persistent growth factor gradients and has significant potential for applications in tissue engineering and regenerative medicine.

\section{Acknowledgements}

This work was supported by Veterans Administration and National Science Foundation (CBET1263994 and IIS-1125412). We would like to thank Lagnojita Signha for the help to develop code for image analysis.

\section{References}

[1] Jin $\mathrm{T}, \mathrm{Xu} \mathrm{X}$, Hereld D. Chemotaxis, chemokine receptors and human disease. Cytokine 2008;44:1-8. doi:10.1016/j.cyto.2008.06.017.

[2] Chung BG, Flanagan L a, Rhee SW, Schwartz PH, Lee AP, Monuki ES, et al. Human neural stem cell growth and differentiation in a gradient-generating microfluidic device. Lab Chip 2005;5:401-6. doi:10.1039/b417651k.

[3] Gillitzer R, Goebeler M. Chemokines in cutaneous wound healing. J Leukoc Biol 2001;69.

[4] Cattaruzza S, Perris R. Proteoglycan control of cell movement during wound healing and cancer spreading. Matrix Biol 2005;24:400-17. doi:10.1016/j.matbio.2005.06.005.

[5] Zhu AJ, Scott MP. Incredible journey: how do developmental signals travel through tissue? Genes Dev 2004;18:2985-97. doi:10.1101/gad.1233104.

[6] Koizumi K, Hojo S, Akashi T, Yasumoto K, Saiki I. Chemokine receptors in cancer metastasis and cancer cell-derived chemokines in host immune response. Cancer Sci 2007;98:1652-8. doi:10.1111/j.1349-7006.2007.00606.x.

[7] Gerhardt H, Golding M, Fruttiger M, Ruhrberg C, Lundkvist A, Abramsson A, et al. VEGF guides angiogenic sprouting utilizing endothelial tip cell filopodia. J Cell Biol 2003;161:116377. doi:10.1083/jcb.200302047.

[8] Griffith LG, Naughton G. Tissue engineering--current challenges and expanding opportunities. Science 2002;295:1009-14. doi:10.1126/science.1069210. 
[9] Genzer J, Efimenko K, Fischer DA, Engineering B, Carolina N, Uni S. Formation Mechanisms and Properties of Semifluorinated Molecular Gradients on Silica Surfaces. Langmuir 2006;22:8532-41.

[10] Zhao B. A Combinatorial Approach to Study Solvent-Induced Self-Assembly of Mixed Poly ( methyl methacrylate )/ Polystyrene Brushes on Planar Silica Substrates: Effect of Relative Grafting Density. Langmuir 2004;20:11748-55.

[11] Matyjaszewski K, Miller PJ, Shukla N, Immaraporn B, Gelman A, Luokala BB, et al. Polymers at Interfaces: Using Atom Transfer Radical Polymerization in the Controlled Growth of Homopolymers and Block Copolymers from Silicon Surfaces in the Absence of Untethered Sacrificial Initiator. Macromolecules 1999;32:8716-24.

[12] Tomlinson MR, Genzer J. Formation of Grafted Macromolecular Assemblies with a Gradual Variation of Molecular Weight on Solid Substrates. Macromolecules 2003;36:2-4.

[13] Kraus T, Stutz R, Balmer TE, Schmid H, Malaquin L, Spencer ND, et al. Printing Chemical Gradients. Langmuir 2005;21:7796-804.

[14] Chung S, Sudo R, Vickerman V, Zervantonakis IK, Kamm RD. Microfluidic Platforms for Studies of Angiogenesis, Cell Migration, and Cell-Cell Interactions. Ann Biomed Eng 2010;38:1164-77. doi:10.1007/s10439-010-9899-3.

[15] Xiaozhen D, Shaoxi C, Qunfang Y, Jiahuan J, Xiaoqing Y, Xin X, et al. A novel in vitro angiogenesis model based on a microfluidic device. Chin Sci Bull 2011;56:3301-9. doi:10.1007/s11434-011-4717-3.

[16] Hwang C, Li D, He BJ, Du Y, Khademhosseini A. Rapid Generation of Biologically Relevant Hydrogels Containing Long-Range Chemical Gradients. Adv Funct Mater 2010:131-7. doi:10.1002/adfm.200901311.

[17] Guarnieri D, De Capua a, Ventre M, Borzacchiello a, Pedone C, Marasco D, et al. Covalently immobilized RGD gradient on PEG hydrogel scaffold influences cell migration parameters. Acta Biomater 2010;6:2532-9. doi:10.1016/j.actbio.2009.12.050.

[18] Oh SH, Kim TH, Lee JH. Creating growth factor gradients in three dimensional porous matrix by centrifugation and surface immobilization. Biomaterials 2011;32:8254-60. doi:10.1016/j.biomaterials.2011.07.027.

[19] Peret BJ, Murphy WL. Controllable Soluble Protein Concentration Gradients in Hydrogel Networks. Adv Funct Mater 2008;18:3410-7. doi:10.1002/adfm.200800218.Controllable.

[20] Guo X, Elliott CG, Li Z, Xu Y, Hamilton DW, Guan J. Creating 3D angiogenic growth factor gradients in fibrous constructs to guide fast angiogenesis. Biomacromolecules 2012;13:326271. doi:10.1021/bm301029a. 
[21] Hellstrom M, Kalen M, Lindahl P, Abramsson A, Betsholtz C. Role of PDGF-B and PDGFRbeta in recruitment of vascular smooth muscle cells and pericytes during embryonic blood vessel formation in the mouse. Development 1999;3055:3047-55.

[22] Chen RR, Silva E a, Yuen WW, Mooney DJ. Spatio-temporal VEGF and PDGF delivery patterns blood vessel formation and maturation. Pharm Res 2007;24:258-64. doi:10.1007/s11095-006-9173-4.

[23] Chiu Y-C, Larson JC, Isom A, Brey EM. Generation of porous poly(ethylene glycol) hydrogels by salt leaching. Tissue Eng Part C Methods 2010;16:905-12. doi:10.1089/ten.TEC.2009.0646.

[24] Sawhney AS, Pathak CP, Hubbell JA. Bioerodible Hydrogels Based on Photopolymerized Poly(ethylene glycol)-co-poly(a-hydroxy acid) Diacrylate Macromers. Macromolecules 1993;26:581-7.

[25] Jiang B, Zhang G, Brey EM. Dual delivery of chlorhexidine and platelet-derived growth factorBB for enhanced wound healing and infection control. Acta Biomater 2013;9:4976-84. doi:10.1016/j.actbio.2012.10.005.

[26] Jiang B, Waller TM, Larson JC, Appel A a, Brey EM. Fibrin-loaded porous poly(ethylene glycol) hydrogels as scaffold materials for vascularized tissue formation. Tissue Eng Part A 2013;19:224-34. doi:10.1089/ten.tea.2012.0120.

[27] Jiang B, Akar B, Waller TM, Larson JC, Appel a a, Brey EM. Design of a composite biomaterial system for tissue engineering applications. Acta Biomater 2014;10:1177-86. doi:10.1016/j.actbio.2013.11.029.

[28] Chiu Y-C, Brey EM, Pérez-Luna VH. A study of the intrinsic autofluorescence of poly (ethylene glycol)-co-(L-lactic acid) diacrylate. J Fluoresc 2012;22:907-13. doi:10.1007/s10895011-1029-6.

[29] Khanna O, Moya ML, Opara EC, Brey EM. Synthesis of multilayered alginate microcapsules for the sustained release of fibroblast growth factor-1. J Biomed Mater Res A 2010;95:632-40. doi:10.1002/jbm.a.32883.

[30] Lawrence JR, Wolfaardt GM, Korber DR. Determination of diffusion coefficients in biofilms by confocal laser microscopy. Appl Environ Microbiol 1994;60:1166-73.

[31] Xu C, Poh YKC, Roes I, O’Cearbhaill ED, Matthiesen ME, Mu L, et al. A portable chemotaxis platform for short and long term analysis. PLoS One 2012;7:e44995. doi:10.1371/journal.pone.0044995.

[32] Zhu J. Bioactive modification of poly(ethylene glycol) hydrogels for tissue engineering. Biomaterials 2010;31:4639-56. doi:10.1016/j.biomaterials.2010.02.044.

[33] Papavasiliou G, Sokic S, Turturro M. Synthetic PEG Hydrogels as Extracellular Matrix Mimics for Tissue Engineering Applications. Biotechnol. - Mol. Stud. Nov. Appl. Improv. Qual. Hum. Life, Prof. Reda Sammour, 2012. 
[34] Martino MM, Briquez PS, Ranga A, Lutolf MP, Hubbell J a. Heparin-binding domain of fibrin(ogen) binds growth factors and promotes tissue repair when incorporated within a synthetic matrix. Proc Natl Acad Sci U S A 2013;110:4563-8. doi:10.1073/pnas.1221602110.

[35] Vila OF, Martino MM, Nebuloni L, Kuhn G, Pérez-Amodio S, Müller R, et al. Bioluminescent and micro-computed tomography imaging of bone repair induced by fibrin-binding growth factors. Acta Biomater 2014;10:4377-89. doi:10.1016/j.actbio.2014.05.028.

[36] Battegay EJ, Rupp J, Iruela-arispe L, Sage EH, Pech M. PDGF-BB Modulates Endothelial Proliferation and Angiogenesis In Vitro via PDGF b Receptors. J Cell Biol 1994;125:917-28.

[37] Cao R, Bråkenhielm E, Pawliuk R, Wariaro D, Post MJ, Wahlberg E, et al. Angiogenic synergism, vascular stability and improvement of hind-limb ischemia by a combination of PDGF-BB and FGF-2. Nat Med 2003;9:604-13. doi:10.1038/nm848.

[38] Schneider IC, Haugh JM. Quantitative elucidation of a distinct spatial gradient-sensing mechanism in fibroblasts. J Cell Biol 2005;171:883-92. doi:10.1083/jcb.200509028.

[39] Amadi OC, Steinhauser ML, Nishi Y, Chung S, Kamm RD, McMahon AP, et al. A low resistance microfluidic system for the creation of stable concentration gradients in a defined 3D microenvironment. Biomed Microdevices 2010;12:1027-41. doi:10.1007/s10544-010-9457-7.

[40] Lienemann PS, Devaud YR, Reuten R, Simona BR, Karlsson M, Weber W, et al. Integrative Biology Locally controlling mesenchymal stem cell morphogenesis by 3D PDGF-BB gradients towards the establishment of an in vitro perivascular niche $\dagger$. Integr Biol 2014;7:101-11. doi:10.1039/C4IB00152D.

[41] Odedra D, Chiu LLY, Shoichet M, Radisic M. Acta Biomaterialia Endothelial cells guided by immobilized gradients of vascular endothelial growth factor on porous collagen scaffolds. Acta Biomater 2011;7:3027-35. doi:10.1016/j.actbio.2011.05.002.

[42] Jeong GS, Kwon GH, Kang AR, Jung BY, Park Y, Chung S, et al. Microfluidic assay of endothelial cell migration in 3D interpenetrating polymer semi-network HA-Collagen hydrogel. Biomed Microdevices 2011;13:717-23. doi:10.1007/s10544-011-9541-7.

[43] DeLong S a, Moon JJ, West JL. Covalently immobilized gradients of bFGF on hydrogel scaffolds for directed cell migration. Biomaterials 2005;26:3227-34. doi:10.1016/j.biomaterials.2004.09.021.

[44] Mancuso MR, Davis R, Norberg SM, O’Brien S, Sennino B, Nakahara T, et al. Rapid vascular regrowth in tumors after reversal of VEGF inhibition. J Clin Invest 2006;116:2610-21. doi:10.1172/JCI24612.

[45] Artel A, Mehdizadeh H, Chiu Y-C, Brey EM, Cinar A. An agent-based model for the investigation of neovascularization within porous scaffolds. Tissue Eng Part A 2011;17:213341. doi:10.1089/ten.TEA.2010.0571. 
[46] Brey EM, Mcinterire L V, Johnston CM, Reece GP, Patrick CW. Three-dimensional, quantitative analysis of desmin and smooth muscle alpha actin expression during angiogenesis. Ann Biomed ... 2004;32:1100-7.

[47] Richardson TP, Peters MC, Ennett AB, Mooney DJ. Polymeric system for dual growth factor delivery. Nat Biotechnol 2001;19:1029-34.

[48] Jiang B, Brey EM. Formation of Stable Vascular Networks in Engineered Tissues. Eberli D, Ed. Regen. Med. tissue Eng. - cells Biomater. Rijeka, Croat. InTech., 2011, p. 477-502.

[49] Gandhi JK, Opara EC, Brey EM. Alginate-based strategies for therapeutic vascularization. Ther Deliv 2013;4:327-41. doi:10.4155/tde.12.163.

[50] Somo SI, Akar B, Bayrak ES, Larson JC, Appel A a, Mehdizadeh H, et al. Pore Interconnectivity Influences Growth Factor-Mediated Vascularization in Sphere-Templated Hydrogels. Tissue Eng Part C Methods 2015;21:773-85. doi:10.1089/ten.TEC.2014.0454.

[51] Barkefors I, Le Jan S, Jakobsson L, Hejll E, Carlson G, Johansson H, et al. Endothelial cell migration in stable gradients of vascular endothelial growth factor A and fibroblast growth factor 2: effects on chemotaxis and chemokinesis. J Biol Chem 2008;283:13905-12. doi:10.1074/jbc.M704917200.

[52] Du Y, Shim J, Vidula M, Hancock MJ, Lo E, Chung BG, et al. Rapid generation of spatially and temporally controllable long-range concentration gradients in a microfluidic device. Lab Chip 2009;9:761-7. doi:10.1039/b815990d.

[53] Brey EM, Uriel S, Greisler HP, McIntire L V. Therapeutic neovascularization: contributions from bioengineering. Tissue Eng 2005;11:567-84. doi:10.1089/ten.2005.11.567.

[54] Roux BM, Cheng M-H, Brey EM. Engineering clinically relevant volumes of vascularized bone. J Cell Mol Med 2015;19:903-14. doi:10.1111/jcmm.12569.

[55] Cheng M, Brey EM, Ph D, Allori A, Satterfield WC, Chang DW, et al. Ovine Model for Engineering Bone Segments 2005;11:214-25.

[56] Cheng M-H, Brey EM, Ulusal BG, Wei F-C. Mandible augmentation for osseointegrated implants using tissue engineering strategies. Plast Reconstr Surg 2006;118:1e-4e. doi:10.1097/01.prs.0000221120.11128.1a. 